\title{
CÁRIE DE ACOMETIMENTO PRECOCE: UMA REVISÃO
}

\section{EARLY CHILDHOOD CARIES: A REVIEW}

\author{
Rafael Gomes Ditterich ${ }^{1}$, Marissol Vasconcellos Romanelli ${ }^{2}$, \\ Márcia Cristina Rastelli ${ }^{3}$, Denise Stadler Wambier ${ }^{4}$ \\ 1,2,3 Universidade Estadual de Ponta Grossa - UEPG, Departamento de Odontologia, \\ Campus em Uvaranas, Ponta Grossa, PR \\ 4 Autor para contato: Universidade Estadual de Ponta Grossa - UEPG, Departamento de \\ Odontologia, Campus em Uvaranas, Ponta Grossa, PR, Brasil; (42) 3220-3111; \\ e-mail: dswambier@uepg.br \\ Recebido para publicação em 05/12/2004 \\ Aceito para publicação em 02/03/2005
}

\section{RESUMO}

Mesmo com o declínio geral da doença cárie em pré-escolares, como sugerido na literatura, existem ainda algumas crianças com significante desenvolvimento dessa doença nos primeiros anos de vida. Esse tipo especial de cárie (Cárie de Acometimento Precoce) se manisfesta em dentes decíduos logo após a sua erupção, representando um sério problema de Saúde Pública. Este artigo objetiva apontar os principais aspectos relacionados à doença, tais como os fatores etiológicos envolvidos, suas principais características e sua prevalência. O comportamento dos pais, que influencia os hábitos alimentares e de higiene de seus filhos, também foi considerado.

Palavras-chave: cárie dentária, bebês, dieta cariogênica

\begin{abstract}
In spite of a general decline in caries prevalence in preschool children, as suggested in the literature, there are some children with significant caries development during their first years of life. This special type of caries (Early Childhood Caries) happens in deciduous teeth just after their eruption and represents a serious problem for Public Health. This article aims at highlighting the main aspects of the disease such as the etiologic factors involved, its main characteristics and prevalence. Parental behaviors that influence the feeding and hygiene of their children were also considered.
\end{abstract}

Key words: dental caries, babies, cariogenic diet 


\section{Introdução}

A cárie é uma doença infecciosa, transmissível que é fortemente modificada pela dieta (Krasse, 1965). Entre os vários fatores etiológicos atuantes no desenvolvimento dessa doença estão: os microrganismos cariogênicos, carboidratos fermentáveis e a suscetibilidade do dente e do hospedeiro (Tanzer, 1989; Seow, 1998). As bactérias aderem a uma fina camada acelular composta por proteínas salivares, fosfoproteínas e lipídios que recobrem as superfícies dentárias, denominada película adquirida. Assim, a formação da placa bacteriana pode ser dividida em três estágios: (1) formação da película adquirida ao esmalte, (2) aderência microbiana inicial e (3) maturação da placa dental. Aceita-se que a cárie é provocada por ácidos resultantes da ação bacteriana sobre carboidratos, determinando a desmineralização da parte inorgânica, seguida da desintegração do componente orgânico do dente (McDonald et al., 2000). A presença de bactérias é fundamental para o desenvolvimento da doença cárie, e muitas delas podem produzir ácido suficiente para desmineralizar a estrutura dentária, porém o Streptococcus mutans tem sido considerado o mais virulento dos microrganismos (McDonald et al., 2000). Na cavidade bucal dos recém-nascidos, essa espécie bacteriana não está presente, e só começa a ser detectada após a erupção dos dentes, sendo a mãe a fonte mais comum de transmissão dessa bactéria cariogênica (Caufield, 1997; Böneker et al., 2004).

A alimentação prolongada, principalmente nas mamadeiras, pode favorecer o aparecimento da cárie rampante, definida por Massler (1945 apud McDonald et al., 2000) como "um tipo de cárie de aparecimento súbito, disseminada, de progressão rápida, resultando no envolvimento pulpar e afetando aqueles dentes usualmente considerados como imunes `a destruição”. Nos primeiros anos de vida, o aspecto clínico dos dentes afetados pela doença é típico e tem um padrão definido: há envolvimento carioso precoce dos dentes anteriores superiores, dos primeiros molares superiores e inferiores, mas geralmente os incisivos no arco inferior não são afetados. A criança adormece e o líquido da mamadeira fica estagnado em volta dos incisivos superiores; o fluxo salivar é diminuído durante o sono e a diluição do líquido ingerido é lenta, promovendo um excelente meio de cultura para as bactérias (McDonald et al., 2000). Evidencia-se, então, o padrão dietético e a contaminação precoce por bactérias cariogênicas como fatores de alto risco para o desenvolvimento da doença cárie em bebês. Objetiva-se neste artigo apresentar os aspectos mais discutidos sobre a doença cárie na primeira infância, fatores etiológicos envolvidos, suas principais características, sua prevalência e as relações comportamentais dos pais influenciando os hábitos alimentares de seus filhos.

\section{Revisão da literatura}

Revisões sistemáticas demonstraram que a cárie de acometimento precoce permanece como sério problema de saúde pública. Existem ainda grandes variações de definições e critérios de diagnóstico, sugerindo que seriam necessárias mais pesquisas para poder se chegar a um consenso sobre o conceito desse tipo de cárie na primeira infância (Nana Lopez, 1998; Ismail e Sohn, 1999; De Grauwe et al., 2004).

Para maior facilidade de compreensão e leitura procuramos abordar esta revisão em três tópicos: Prevalência, padrão de cárie e fatores de risco.

\subsection{Prevalência da doença cárie}

No que diz respeito à prevalência da doença cárie em bebês, observa-se variação percentual entre diferentes localidades e classes sociais. Alguns estudos foram realizados objetivando apenas determinar o ceo-d e não consideraram as superfícies dentárias envolvidas e os hábitos do hospedeiro.

Em estudos realizados na cidade de Ponta Grossa, verificou-se alta prevalência de lesões de cárie em bebês e que os incisivos superiores foram os dentes mais afetados (Wambier e Deliga, 1995; Moreira et al. 2001; Wambier et al., 2004).

Entre os bebês examinados nas creches de Salvador, 55\% apresentavam cárie, com maior freqüência nos dentes anteriores. Constatou-se uma associação positiva entre a doença cárie, presença de aleitamento noturno e acúmulo de biofilme dental (Barros et al., 2001).

O exame de crianças sauditas para verificar a presença de cárie de mamadeira, utilizando como crité- 
rio a presença de pelo menos dois dentes com lesões de cárie na superfície vestibular de incisivos superiores, demonstrou a ocorrência desse padrão de cárie em $27,3 \%$ das crianças, sendo que os incisivos centrais superiores foram os dentes mais afetados (Wyne et al. 2001).

Na pesquisa realizada por Jin et al. (2003), 56\% das crianças (6-59 meses) eram portadoras de cárie de acometimento precoce e entre elas, $47 \%$ possuíam um quadro severo da doença. As lesões não cavitadas também foram incluídas e os pais foram questionados, objetivando identificar os fatores de risco. As crianças que mamavam com soluções açucaradas mostraram um quadro severo da doença e aquelas cujos pais relataram menor freqüência de petiscos entre as refeições tinham menor prevalência.

Baseados no critério de que a presença de lesões cariosas nos quatro incisivos superiores é indicativo de cárie de acometimento precoce, Babu e King (2003), ao examinarem 530 crianças de 8 a 48 meses em Kerala (Índia), diagnosticaram que $12 \%$ delas apresentavam esse padrão de cárie. Segundo essa pesquisa, os grupos de alto risco para o desenvolvimento de lesões cariosas apresentavam pobre higiene bucal, consumiam doces à vontade e pertenciam a um nível sócio-econômico mais baixo.

A cárie de acometimento precoce tem etiologia multifatorial, esta foi a conclusão de um estudo comparativo entre crianças chinesas e de Hong Kong, no qual não foram detectadas diferenças significantes na prevalência de cárie, nos hábitos de alimentação e de higiene bucal. Essas duas populações possuem cultura semelhante e a prevalência da doença foi de $19 \%$ e $17 \%$, respectivamente (King et al., 2003).

Dois estudos foram feitos na Itália por Ferro et al. (2004), sendo que 19,7\% das crianças possuíam cárie de acometimento precoce. Os imigrantes apresentavam percentuais maiores (52\%) em comparação com as crianças nativas (18\%). Usando os critérios de diagnóstico para cárie de mamadeira, os autores relataram que no estudo de 1994, o percentual foi de 11,9\% e neste último foi de 6,5\%. Dentes não cavitados não foram incluídos.

\subsection{Padrão de cárie na primeira infância}

Conforme dados da literatura, mesmo com o declínio global da prevalência de cárie constatado nas últimas décadas nas diferentes faixas etárias, ainda permanece em algumas crianças um tipo especial de cárie, denominada recentemente de cárie de acometimento precoce.

O termo E.C.C., sigla do inglês "Early Childhood Caries”, foi sugerido em 1994, em um trabalho para o centro de controle e prevenção de doenças (Kaste e Gift, 1995). Outras terminologias já foram empregadas, tais como: cáries labiais, cáries de incisivos, cárie de mamadeira, cárie de amamentação, cáries rampantes em pré-escolares (Bowen, 1998; Ismail e Sohn, 1999), cárie de bebê(McDonald et al., 2000) e cárie negligenciada, que se refere a estágios mais avançados de destruição dentária (Walter et al., 1996).

Stevens e Freeman (2004) empregaram o termo "nursing caries mothering”, para destacar a responsabilidade da mãe no desenvolvimento da cárie de acometimento precoce, uma vez que o emprego da mamadeira está associado a comportamentos, tais como a conveniência materna.

Cárie de mamadeira, sempre foi o termo mais freqüentemente encontrado nos textos e livros de Odontopediatria, porém nem sempre a causa da doença é o uso da mamadeira. Chupetas adoçadas com mel ou açúcar, o aleitamento natural freqüente, são condições que também podem determinar o surgimento de lesões cariosas e com aspecto semelhante.

Walter et al., (1996) relataram que cárie do tipo mamadeira ou cárie de aleitamento são denominações diferentes para uma mesma doença aguda que afeta a criança ainda no primeiro ano de vida. O seu aparecimento depende da presença de um substrato (resíduos de leite materno, bovino ou hábitos de adoçar a chupeta com mel), tendo como coadjuvante a ausência de limpeza bucal.

A cárie de acometimento precoce envolve um ou mais dentes que se apresentam com lesões brancas ou cavitadas, perdidos (devido à cárie), ou dentes com superfície restaurada desde os primeiros anos de vida até a idade de cinco anos (Drury et al., 1999). Esse padrão de cárie pode também apresentar-se de forma mais severa com muitos dentes envolvidos e rápida evolução, afetando principalmente as superfícies consi- 
deradas de baixo risco, como as faces vestibulares de incisivos e faces linguais e vestibulares de molares superiores e inferiores (Ripa, 1988).

Inicialmente, observa-se nos incisivos superiores a presença de manchas esbranquiçadas localizadas na margem gengival (figura 1A), as quais podem apresentar rápida progressão com cavitação (figuras 1BC), estendendo-se para outras superfícies (figura 1D). Na ausência de medidas preventivas, a evolução do processo carioso pode determinar ampla destruição da coroa dentária (figura 1E), até a destruição total, deixando apenas as raízes (Dilley et al., 1980; Ripa, 1988).

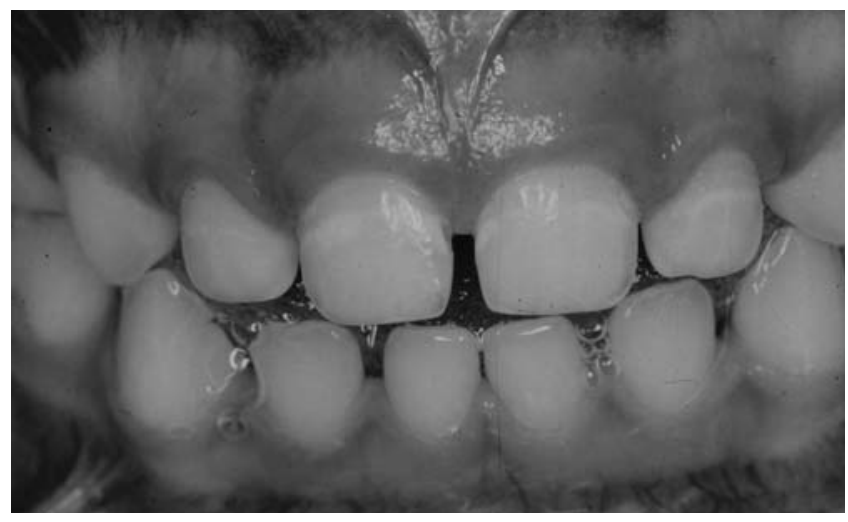

A

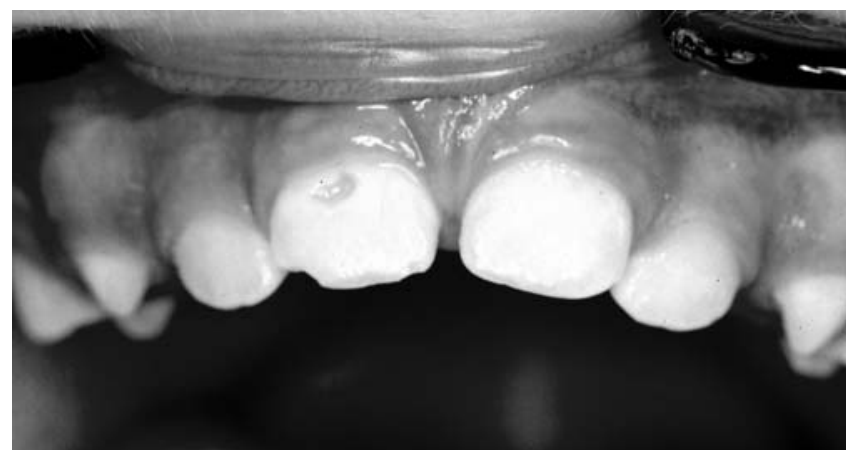

B

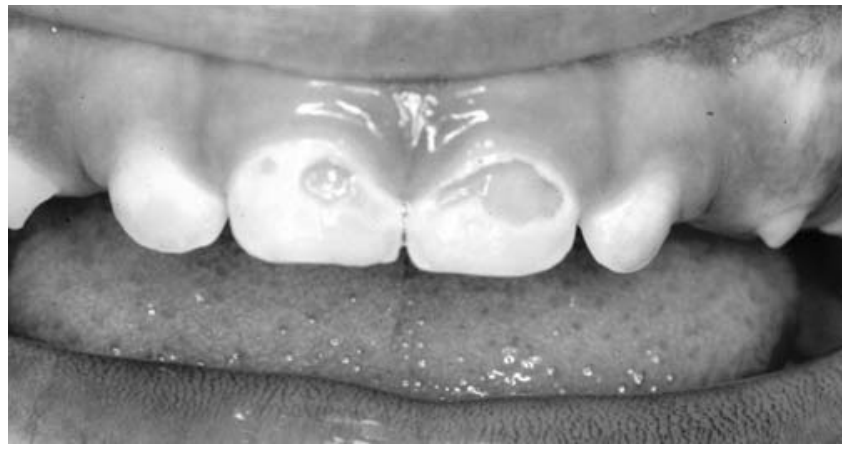

C

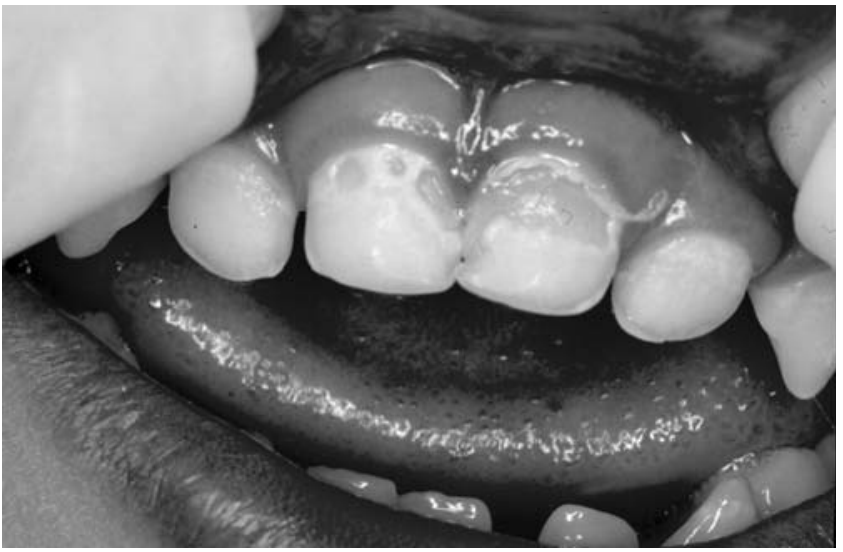

D

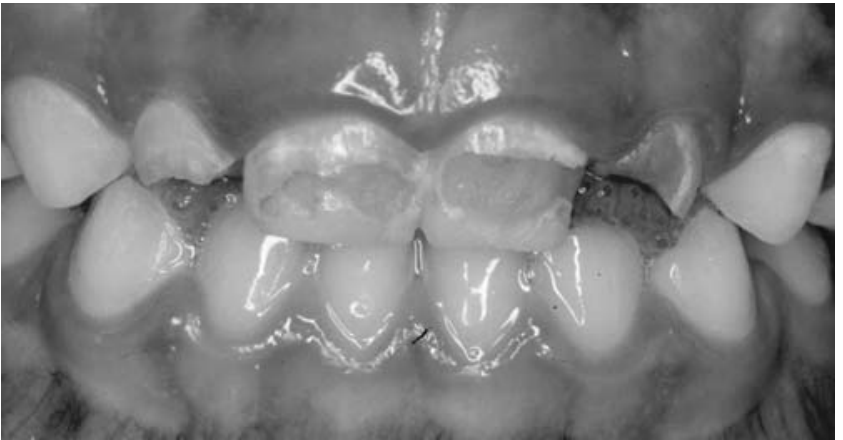

E

Figuras 1A-E - Cárie de Acometimento Precoce. Lesões cariosas ativas em dentes decíduos que exemplificam a evolução do processo carioso. A figura 1A mostra lesões brancas nos incisivos, a figura 1B apresenta lesão cavitada no dente 51. Nota-se na figura 1C, lesões cariosas nas superfícies vestibulares e na figura D, a lesão alcançou as superfícies mesiais dos dentes 51 e 62. A ausência de intervenção permite ampla destruição coronária, como mostra a figura E. 
Algumas vezes, segundo Ismail e Sohn (1999) a cárie precoce pode acometer além demolarese incisivos superiores, também os caninos e incisivos inferiores. Normalmente, esses dentes são menos atingidos, devido à proximidade com as glândulas salivares. Durante o sono ocorre uma redução da saliva e conseqüentemente a capacidade de proteção é diminuída, e os resíduos alimentares com açúcar são fermentados e metabolizados por microrganismos bucais produzindo ácidos desmineralizantes (Ripa, 1988; Horowitz, 1998).

\subsection{Fatores de risco na infância}

Alguns fatores de risco são próprios da infância, tais como a prematura colonização por $S$. mutans, a freqüência da amamentação, a ingestão de sacarose, criando um meio favorável para o crescimento dessa bactéria cariogênica no biofilme dental. Outros fatores que podem interferir nesse processo são a imaturidade do sistema de defesa do hospedeiro, assim como comportamentos paternos associados com alimentação e higiene bucal (Bowen, 1998; Horowitz, 1998; Seow, 1998).

As crianças com dentes colonizados precocemente por bactérias cariogênicas apresentam uma elevada experiência de cárie se comparadas com aquelas colonizadas mais tarde, ou não colonizadas (Alaluusua e Renkonen, 1983; Köhler et al., 1984).

No Brasil, Mattos-Graner et al. (1998) verificaram que $71 \%$ dos bebês na faixa etária de 12-18 meses já estavam infectados por $S$. mutans, e esses valores subiam para 88\% na faixa etária de 25-30 meses.

Os níveis de $S$. mutans foram considerados preditores significantes para o desenvolvimento da cárie precoce em crianças. Altos escores de cárie severa foram verificados em crianças com aleitamento natural e alta contagem de $S$. mutans e também nas crianças de baixa renda que eram cuidadas por pessoas com dentes cariados (Vachirarojpisan et al., 2004).

Em recente revisão da literatura, Bönecker et al. (2004) concluíram que é alta a prevalência de S.mutans em bebês, a mãe por meio da saliva éa principal fonte de transmissão e que o período crítico para a aquisição dessas bactérias cariogênicas, denominado de “janela de infectividade”, abrange a faixa etária de 19-31 meses. A respeito da faixa etária de contamina- ção, existem ainda controvérsias.

A sacarose é um dos açúcares mais utilizados e tem um potencial cariogênico maior que outros carboidratos (Gustafsson et al., 1954; Newbrun, 1988), pois facilita a aderência bacteriana. Com a presença de sacarose, o $S$. mutans forma um polissacarídeo extracelular pegajoso, semelhante ao dextrano e essa capacidade permite a formação de colônias fortemente aderidas às superfícies dentárias (Krasse, 1988).

Em pesquisa realizada com bebês de uma instituição pública não foi demonstrada associação entre aleitamento natural e artificial prolongados com cárie dentária. Contudo, houve correlação significativa entre consumo de sacarose, refrigerantes e alimentos sólidos cariogênicos com a prevalência da doença cárie (Valle et al., 2001).

Karjalainen et al. (2001) acompanharam 135 crianças desde os três anos de idade e verificaram que aquelas que consumiam sacarose mais de uma vez na semana aos três anos de idade, também consumiam mais açúcar aos seis anos e, conseqüentemente, apresentavam maior atividade da doença cárie.

Fraiz e Walter (2001) concluíram que a presença de placa visível nos incisivos superiores é devida à falta de uma educação formal dos responsáveis, ao alto consumo de açúcar e ao uso de mamadeira durante o sono, fatores fortemente associados à presença de cárie em bebês. Destacaram que a placa bacteriana visível nos incisivos superiores é indicativo clínico de padrões inadequados de higiene e dieta.

Vários estudos sugeriram que a criança com cárie precoce tem uma alta freqüência de consumo de açúcar, não somente pela amamentação com mamadeiras (Albert et al., 1988; Marino et al., 1989; Wendt et al., 1991), mas também ingerindo alimentos sólidos (King, 1978; Persson et al., 1985; Tsubouchi et al., 1995). Segundo Hallett e O’Rourke (2003), o risco da cárie de acometimento precoce pode ser significantemente aumentado devido aos hábitos alimentares das crianças, tais como: não ter acesso à amamentação materna até os 12 meses de idade, fazer amamentação noturna e ainda deve ser considerada a freqüência e duração da amamentação diurna com a mamadeira.

Independentemente do conteúdo da mamadeira, a inserção do bico na boca da criança tem várias conseqüências. As superfícies palatinas e vestibulares dos incisivos superiores ficam inacessíveis ao fluxo salivar. 
Isso pode ser uma importante particularidade da criança que se alimenta com mamadeira ou alimentos sólidos e usa chupeta. O hábito de provar os alimentos ou limpar a chupeta com a saliva materna pode determinar a transferência de bactérias cariogênicas aos menores. Já foi demonstrado que o $S$. mutans é transmitido por via oral, da mãe para o bebê, e existe relação entre o número dessas bactérias nos pares de mães e bebês (Davey e Rogers, 1984; Berkowitz e Jones, 1985; Brown et al., 1985).

Pesquisas de alta qualidade, longitudinais e com modelo experimental adequado, são escassas, porém existem evidências de que a aquisição precoce de bactérias cariogênicas, torna a criança mais suscetível ao desenvolvimento da doença cárie. Contudo, esse fator negativo pode ser compensado por outros positivos, tais como higiene adequada e dieta não cariogênica (Harris et al., 2004).

Um dos fatores mais importantes do hospedeiro, que determina a resistência à cárie dentária, é a qualidade e o estado do esmalte (Krasse, 1988). Estudos epidemiológicos sugerem que no período logo após a erupção, e anterior à maturação final, o dente é mais suscetível à cárie (Carlos e Gittelsohn, 1965). Dessa forma, em muitas crianças, a combinação de esmalte imaturo com uma microbiota cariogênica e freqüente ingestão de carboidratos fermentáveis confere uma particular suscetibilidade à cárie dental (Seow, 1998).

Alguns pesquisadores procuraram expandir o modelo microbiológico básico da cárie de acometimento precoce, incluindo também os fatores sociais, demográficos e comportamentais tais como: etnia, renda familiar, nível de educação materna, status familiar, hábitos de escovação e conhecimento e crenças paternas (Reisine et al., 1994; Tinanoff e O’Sullivan, 1997; Fraiz e Walter, 2001; Wyne, 2001).

Nas classes sociais de baixo poder aquisitivo, observa-se maior prevalência de cárie e maior freqüência de preparo de mamadeiras com açúcar (Grindefjord, 1993). Segundo Furlani (1993) um grau elevado de instrução paterna e melhor nível econômico familiar resultam em um maior nível de saúde, porque os pais têm um melhor conhecimento sobre a higiene pessoal, além de maior acesso à educação e à prevenção da cárie dental. O alto percentual de lesões cariosas em bebês oriundos de famílias de baixa renda e escolaridade, permitiu concluir que as condições sociais são realmente limitantes, tornando essas comunidades dependentes do serviço público, nem sempre acessível a todos (Alves et al., 2001).

A cárie de acometimento precoce constitui-se num problema social grave na Tailândia, atingindo $82,8 \%$ das crianças (15-19 meses) que vivem na zona rural e pertencem às famílias de baixa renda e escolaridade (Vachirarojpisan et al., 2004). Fatores como condição econômica, social e cultural têm demonstrado uma alta probabilidade de desenvolver a doença, porém até agora não se sabe o impacto real que esses fatores têm sobre a saúde bucal infantil (Horowitz, 1998).

Fatores psicossociais e comportamentais podem interagir no desenvolvimento da cárie precoce. As crianças de grupos étnicos minoritários que moram em ambientes de baixa renda, com apenas um dos pais e com mínima formação educacional, desenvolveram esse padrão de cárie, porém não se pode dizer que todas as crianças que apresentam essas condições realmente desenvolverão a doença (Quiñonez et al., 2001).

\section{Considerações finais}

Na prevenção e tratamento da cárie de acometimento precoce, os cirurgiões-dentistas devem trabalhar com a interação pais e filhos, pois os pais são os responsáveis pela alimentação e cuidados de saúde bucal. Nesse processo deve haver conhecimento da multifatoriedade da doença e que a dieta é somente um dos fatores envolvidos. Ao planejar programa de controle de cárie é essencial considerar a etiologia multifatorial da cárie dentária e não confiar somente em medidas que aumentem a resistência dos dentes (Hausen, 2004).

No futuro, a educação e promoção da saúde bucal devem dirigir-se aos fatores de risco da doença cárie. Os programas de saúde financiados pela ação pública devem desenvolver estratégias efetivas para controle e redução, tendo como meta principalmente as crianças de baixo nível sócio-econômico.

A presença constante de campanhas de conscientização dos pais e profissionais da saúde sobre a importância da amamentação natural é fundamental, já que o uso precoce de mamadeira tem sido um dos 
principais fatores para o desenvolvimento da cárie de acometimento precoce.

Na realidade, a doença cárie em crianças de tenra idade não é fato recente, e tem sido relacionada a vários fatores, principalmente aos hábitos inadequados, e a literatura odontológica objetiva encontrar uma denominação mais adequada para se referir a essa patologia.

\section{REFERÊNCIAS}

1. ALALUUSUA, S.; RENKONEN, O. V. Streptococcus mutans establishment and dental caries experience in children from 2 to 4 years old. Scand J Dent Res, Copenhagen, v. 91, p. 453-7, 1983.

2. ALBERT, R. J.; CANTIN, R.Y.; CROSS H. S.; CASTALDI, C. R. Nursing caries in the nuit children. J Can Dent Assoc, Ottawa, v. 54, p. 751-8, 1988.

3. ALVES, F; MOREIRA, C. S.; KUMMER, T. R.; CUMAN, V.; WAMBIER, D. S.; KOZLOWSKI, Jr. V. Prevalência da doença cárie em bebês de baixo nível sócio-econômico-cultural. ENCONTRO ANUAL DE INICIAÇÃO CIENTÍFICA, Ponta Grossa: UEPG, Anais..., p. 322, 2001.

4. BABU, J; KING, N. M. Early childhood caries lesions in preschool children in Kerala, India. Pediatric Dentistry, Chicago, v. 25, p. 594-600, 2003.

5. BARROS, S. G.; ALVES, A. C.; PUGLIESE, L. S.; REIS, S. R. A. Contribuição ao estudo da cárie dentária em crianças de 030 meses. Pesqui Odontol Bras, São Paulo, v. 15, p. 215-22, 2001.

6. BERKOWITZ, R. J.; JONES, P. Mouth- to- mouth transmission of the bacterium Streptococcus mutans between mother and child. Arch Oral Biol, v. 30, p. 377-379, 1985.

7. BÖNECKER, M.; ARDENGHI, T. M.; TRINDADE, C. P.; CURY, P. Transmissão vertical de Streptococcus mutans e suas implicações. JBP-Rev Ibero-Am Odontopediatr Odontol Bebe. Curitiba, v. 7, n. 37, p. 297-303, 2004.

8. BOWEN, W. H. Response to Seow: biological mechanisms of early childhood caries. Community Dent Oral Epidemiol, Copenhagen, v. 26, suplemento 1, p. 28-31, 1998.

9. BROWN, J. P.; JUNNER, C.; LIEW, V. A study of Streptococcus mutans levels in both infants with bottle caries and their mothers. Aust Dent J, North Sydney, v. 30, p. 96-98, 1985.

10. CARLOS, J. P.; GITTELSOHN, A. M. Longitudinal studies of the natural history of caries II. Arch Oral Biol, v. 10, p. 739$51,1965$.

11. CAUFIELD, P. W. Dental caries a transmissible and infectious disease, revisited: a position paper. Pediatric Dentistry, Chicago, v. 19, p. 491-498, 1997.

12. DAVEY, A. L.; ROGERS, A. H. Multiple types of the bacterium Streptococcus mutans in the human mouth and their intra-family transmission. Arch Oral Biol, v. 29, p. 453-460, 1984.

13. De GRAUWE, A.; APS, J. K.; MARTEUS, L.C. Early childhood caries (ECC): What's in a name? Eur J Paediatr Dent, v. 5, n. 2, p. 62-70, 2004.

14. DILLEY, G. J.; DILLEY, D. H.; MACHEN, J. B. Prolonged nursing habit: a profile of patients and their families. Asdc $\mathbf{J}$ Dent Child, Copenhagen, v. 47, p. 102-8, 1980.

15. DRURY, T. F.; HOROWITZ, A. M.; ISMAIL, A. I.; MAERTENS, M. P.; ROZIER, G.; SELWINTZ, R. H. Diagnosing an reporting early childhood caries for research purposes. J Public Health Dent, Raleigh, v. 59, n. 3, p. 192-7, 1999.

16. FERRO, R.; BESOSTRI,A.; MENEGHETTI, B.; BEGHETTO, M. Comparison of data on Early Childhood Caries (ECC) with previous data for Baby Bottle Tooth Decay (BBTD) in an Italian kindergarten population. Eur J Paediatr Dent, v. 5, n. 2, p. 715, 2004.

17. FRAIZ, F. C.; WALTER, L. R. F. Estudo dos fatores associados à cárie dental em crianças que receberam atendimento odontológico precoce. Pesqui Odontol Bras, São Paulo, v. 15, p. 201-7, 2001

18. FURLANI, P. A. Influências dos aspectos sócio-culturais na prevalência da cárie dentária em escolares de Jaraguá do Sul. Jaraguá do Sul, 1993. 64p. Monografia (Especialização em Odontologia Preventiva e Social)-Universidade Federal do Paraná.

19. GRINDEFJORD, M. Caries prevalence in 2.5 year-old children. Caries Res, Basel, v. 27, p. 505-510, 1993.

20. GUSTAFSSON, B. E.; QUENSEL, C. E.; SWENANDERLANKE, L.; LUNDQUIST, C.; GRAHNER, H.; BONOW, B. E. The Vipeholm dental caries study: survey of the literature on carbohydrates and dental caries. Acta Odontol Scand, Oslo, v. 11, p. 207-31, 1954.

21. HALLET, K. B.; O’ROURKE, P. K. Social and behavioural determinants of early childhood caries. Aust Dent J, North Sydney, v. 48, n. 1, p. 27-33, 2003.

22. HARRIS, R.; NICOLLI, A. D.; ADAIR, P. M.; PINE, C. M. Risk factors for dental caries in young children: a systematic review of the literature. Community Dent Health, Hampshire, v. 21, suplemento 1, p. 71-85, 2004.

23. HAUSEN, H. How to improve the effectiveness of cariespreventive programs based on fluoride. Caries Res, Basel, v. 38, n. 3, p. 263-267, may.jun., 2004.

24. HOROWITZ, H. S. Research issues in early childhood 
caries. Community Dent Oral Epidemiol, Copenhagen, v. 26, suplemento 1, p. 67-81, 1998.

25. ISMAIL, A.; SOHN, W. A systematic rewiew of clinical daignostic criteria of early childhood caries. J Public Health Dent, Raleigh, v. 59, n. 3, p. 171-91, 1999.

26. JIN, B. H.; MA, D. S.; MOON, H. S.; PAIK, D. I.; HAHN, S. H.; HOROWITZ, A. M. Early childhood caries: prevalence and risk factors in Seoul, Korea. J Public Health Dent, Raleigh, v. 63, n. 3, p. 183-8, 2003.

27. KARJALAINEN, S.; SÖDERLING, E.; SEWÓN, L.; LAPINLEIMU, H. A prospective study on sucrose consumption, visible plaque and caries in children from 3 to 6 years of age. Community Dent Oral Epidemiol, Copenhagen, v. 29, n. 2, p.136-42, 2001.

28. KASTE, L. M.; GIFT, H. C. Inappropriate infant bottle feeding - Status of the healthy people 2000 objective. Arch Pediatr Adolesc Med, v. 149, p. 786-91, 1995.

29. KING, J. M. Patterns of sugar consumption in early infancy. Community Dent Oral Epidemiol, Copenhagen, v. 6, n. 2, p. 47-52, 1978.

30. KING, N. M.; WU, I. I.; TSAI, J. S. Caries prevalence and distribuition, and oral health habits of zero-to-four-year-old children in Macau, China. Asdc J Dent Child, Chicago, v. 70, n. 3, p. 243-9, 2003.

31. KÖHLER, B.; ANDRÉEN, I.; JOHNSSON, B. The effect of caries-preventive measures in mothers on dental caries and oral presence of the bacteria Streptococcus mutans and lactobacilli in their children. Arch Oral Biol, v. 29, p. 879-83, 1984.

32. KRASSE, B. The effect of caries inducing streptococci in hamsters fed diets with sucrose or glucose. Arch Oral Biol, v. 10, p. 223-6, 1965.

33. KRASSE, B. Risco de cáries. 2.ed. São Paulo: Quintessence, 1988, p. 15-28.

34. MARINO, R.; BOMZE, K.; SCHOLL, T. O.; ANHALT, H. Nursing bottle caries: characteristics of children at risk. J Clin Paediatr, v. 28, n. 2, p. 129-31, 1989.

35. MATTOS-GRANER, R. O.; ZELANTE, F.; LINE, R. C.; MAYER, M. P. Association between caries prevalence and clinical, microbiological and dietary variables in 1.0 to 2.5-yearold Brazilian children. Caries Res, Basel, v. 32, n. 5, p. 319-23, 1998.

36. McDONALD, R. E.; AVERY, D. R.; STOOKEY, G. K. Cárie dentária na criança e no adolescente. In: McDONALD, R. E.; AVERY, D. R. Odontopediatria, 7. ed. Rio de Janeiro: Guanabara Koogan, 2000, p. 151-177.

37. MOREIRA, C. S.; TEIXEIRA, F.; KUMMER, T. R.; CUMAN, V.; WAMBIER, D. S. Perfil de saúde bucal na primeira infância. CONGRESSO NACIONAL DE INICIAÇÃO CIENTÍFICA,
2001, Anais..., São Paulo, 2001, v. 2, p. 376.

38. NANA LOPEZ, G. M. Response to Edelstein: policy issues in early childhood caries. Community Dent Oral Epidemiol, Copenhagen, v. 26, suplemento 1, p. 104-5, 1998.

39. NEWBRUN, E. Cariologia. 2.ed. São Paulo: Santos, 1988. $187 p$.

40. PERSSON, L. A.; HOLM, A. K.; ARVIDSSON, S.; SAMUELSON, G. Infant feeding and dental caries - a longitudinal study of Swedish children. Swedish Dental Journal, Stockholm, v. 9, n. 2, p. 201-6, 1985.

41. QUIÑONEZ, R. B.; KEELS, M.A.; VANN JR, W. F.; MCIVER, F. T.; HELLER, K. Early childhood caries: analysis of psychosocial and biological factors in a high-risk population. Caries Res, Basel, v. 35, p. 376-383, 2001.

42. RIPA, L. W. Nursing caries: a comprehensive review. Pediatric Dentistry, Chicago, v. 10, p. 268-82, 1988.

43. REISINE, S.; LITT, M.; TINANOFF, N. A biopsychosocial model to predict caries in preschool children. Pediatric Dentistry, Chicago, v. 16, p. 413-418, 1994.

44. SEOW, W. K. Biological mechanisms of early childhood caries. Community Dent Oral Epidemiol, Copenhagen, v. 26, suplemento 1, p. 8-27, 1998.

45. STEVENS, A.; FREEMAN, R. The role of the mother-child interaction as a factor in nursing caries (ECC): a preliminary communication. Eur J Paediatr Dent, v. 5, n. 2, p. 81-5, 2004.

46. TANZER, J. M. On changing the cariogenic chemistry of coronal plaque. J Dent Res, Washington, v. 68, p.1576-87, 1989.

47. TINANOFF, N.; O’SULLIVAN, D. M. Early Childhood caries: overview and recent finding. Pediatric Dentistry, Chicago, v. 19, n. 1, p. 12-16, 1997.

48. TSUBOUCHI, J.; TSUBOUCHI, M.; MAYARD, R. J., DOMOTO; P. K.; WEINSTEIN, P. A. A study of dental caries and risk factors among native American infants. Asdc J Dent Child, Chicago, v. 62, p. 283-7, 1995.

49. VACHIRAROJPISAN, T. et al. Early childhood caries in children aged 6-19 months. Community Dent Oral Epidemiol, Copenhagen, v. 32, n. 2, p. 133-42, 2004.

50. VALLE, D. D.; MODESTO, A. S.; RIBEIRO, I. P. Hábitos alimentares e prevalência da doença cárie em bebês. Rev Bras Odontol, Rio de Janeiro,b v. 58, p. 332-5, 2001.

51. WALTER, L. R. F.; FERELLE, A.; ISSAO, M. Odontologia para o bebê. São Paulo: Artes médicas, 1996, p. 75-92.

52. WAMBIER, D. S.; DELIGA, A.G. Estudo da prevalência da cárie dentária em bebês. PUBLICATIO UEPG- Ciências Biológicas e da Saúde, v. 3, n. 3, p. 7-14, 1995. 
53. WAMBIER, D. S.; BOSCO,V. L.; VANESSA, C.; SMIGUEL, O.; ELOY, T. C. Prevalência e distribuição de lesões de cárie em bebês. PUBLICATIO UEPG- Ciências Biológicas e da Saúde, v. 10, n. 1, p. 15-22, 2004.

54. WENDT, I. K.; HALLONSTAIN, A.; KOCH, G. Dental caries in one and two- year-old children living in Sweden Part I - a longitudinal study. Swedish Dental Journal, Stockholm, v. 5, n. 1, p. 1-6, 1991.

55. WYNE, A.; DARWISH, S.; ADENUBI, J.; BATTATA, S.; KHAN, $\mathrm{N}$. The prevalence and pattern of nursing caries in saudi preschool children. Int J Paediatr Dent, Oxford, v. 11, n. 5, p. 361-364, 2001. 